\title{
Clinical outcomes of patients with metachronous second primary lung adenocarcinomas
}

\author{
Heng Zhaol,* \\ Haitang Yang ${ }^{2-4, *}$ \\ $\mathrm{Ke} \mathrm{Han}{ }^{5, *}$ \\ Jianlin $X u^{6}$ \\ Feng $\mathrm{YaO}^{5}$ \\ Yang Zhao ${ }^{5}$ \\ Liwen Fan $^{5}$ \\ Haiyong $\mathrm{Gu}^{5}$ \\ Zhenya Shen ${ }^{1, *}$
}

'Department of Cardiovascular Surgery of First Affiliated Hospital of Soochow University, Suzhou, People's Republic of China; ${ }^{2}$ Division of General Thoracic Surgery, Inselspital, Bern University Hospital, ${ }^{3} \mathrm{Graduate}$ School for Cellular and Biomedical Sciences, ${ }^{4}$ Department of Clinical Research, University of Bern, Bern, Switzerland; ${ }^{5}$ Department of Thoracic Surgery, Shanghai Chest Hospital, Shanghai Jiao Tong University, Shanghai, ${ }^{6}$ Department of Pulmonary, Shanghai Chest Hospital, Shanghai Jiao Tong University, Shanghai, People's Republic of China

*These authors contributed equally to this work

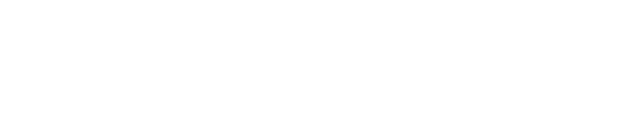

Background: The incidence of adenocarcinomas as multiple primary lung cancers (MPLCs) is increasing. How to determine the treatment strategies of MPLCs, especially second primary lung adenocarcinomas (SPLACs), and the prognostic factors associated with it are unclear.

Methods: The clinical records of patients undergoing surgery for second adenocarcinomas based on Martini-Melamed criteria between 2001 and 2014 were retrospectively reviewed. Survival rates were calculated by the Kaplan-Meier method and compared using the log-rank test. Multivariate analysis was conducted using the Cox proportional hazards model.

Results: A total of 115 patients with SPLACs were identified based on Martini-Melamed criteria. With respect to the second resections, three subgroups with low- (adenocarcinoma in situ, $n=6$; minimally invasive adenocarcinoma, $n=19$ ), intermediate- (lepidic, $n=9$; acinar, $n=40$; papillary, $n=23$ ), and high-grades (solid, $n=9$; micropapillary, $n=2$; invasive mucinous, $n=7$ ) were assigned. The 5-year overall survival (OS) rates from the time of the first and the second resections were $86.5 \%$ and $69.5 \%$, respectively. Cox multivariate analysis identified computed tomography (CT) morphology of SPLACs (ground glass opacity predominant versus solid predominant; hazard ratio $[\mathrm{HR}]=0.42 ; P=0.036$ ), histologic classification (same/similar vs different; $\mathrm{HR}=0.06 ; P<0.001$ ), pathologic stage of the primary (stage I vs II; HR=0.20; $P=0.015$ ) and second tumors (stage I vs IIIa; HR=0.21; $P=0.002$ ), and histologic grade of SPLACs (low- vs high-grade, $\mathrm{HR}=0.05, P=0.016$; intermediate- $\mathrm{vs}$ high-grade, $\mathrm{HR}=0.37, P=0.027$ ) as significantly favorable prognostic factors for OS.

Conclusion: In addition to pathologic stage of the initial tumors and histologic classification, pathologic stage and CT morphology of SPLACs were identified as predictors of survival. The histologic grade of SPLACs based on the new adenocarcinoma classification could provide additional prognostic information.

Keywords: multiple primary lung cancer, metachronous, adenocarcinoma

\section{Introduction}

With the imaging technology advancement, and increasing awareness of early lung cancer screening, a growing number of cases presented with multiple primary lung cancer (MPLC) in clinical manifestation have taken place. Many studies have demonstrated significantly promising survival outcomes in patients with synchronous and metachronous MPLCs after surgical intervention. ${ }^{1-4}$

The most common histology of second MPLC is adenocarcinoma. ${ }^{1,2,4}$ Solitary lung adenocarcinoma has been widely investigated since the proposal by a joint working group of the International Association for the Study of Lung Cancer, American Thoracic Society, and European Respiratory Society (IASLC/ATS/ERS) in 2011. ${ }^{5}$ However, the prognosis of lung adenocarcinomas as the second MPLC has not been studied in detail. In addition, the characteristics and surgical treatment of the initial lung cancer can also
Department of Cardiovascular Surgery of First Affiliated Hospital of Soochow University, No 188 Shizi Street, Suzhou 215006, People's Republic of China

$\mathrm{Tel}+865 \mid 2$ I36 062I 0812

Fax +865126778 I35।

Email shen_zhenya@I63.com
OncoTargets and Therapy 2017:10 295-302

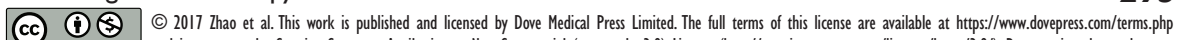
cc) hereby accept the Terms. Non-commercial uses of the work are permitted without any further permission from Dove Medical Press Limited, provided the work is properly attributed. For peminsion for commercial use of this work, please see paragraphs 4.2 and 5 of our Terms (https://www.dovepress. com/terms.php). 
potentially affect the prognosis of MPLC patients, which was not considered in previous studies. ${ }^{1,3,4}$

In this study, the clinicopathologic features and prognosis of patients with a second primary lung adenocarcinoma (SPLAC) undergoing surgery were assessed.

\section{Patients and methods}

\section{Patients}

The study was approved by the ethics committee Patients of Shanghai Chest Hospital and the written informed consent was obtained from each participant in accordance with the institutional guidelines. All treatments were carried out in accordance with the approved guidelines and regulations. After looking through all the medical records of patients undergoing pulmonary resection for non-small cell lung cancer (NSCLC) during the period between January 2001 and December 2014, patients who underwent second resections for lung adenocarcinomas were retrospectively reviewed. A second primary lung cancer (SPLC) refers to a new primary lung cancer that develops after curative intent therapy for a first primary lung cancer. Both the initial and the second resections of NSCLC had been performed at the Department of Thoracic Surgery of Shanghai Chest Hospital, Shanghai, People's Republic of China.

Inclusion criteria mainly based on Martini-Melamed criteria: ${ }^{6}$ presence of tumors with different histologies (eg, adenocarcinoma versus squamous cell carcinoma), tumors of similar histology but arising from separate foci (eg, in the case of squamous cell carcinoma, the presence of in situ carcinoma in both tumors), a disease-free interval between the two lesions for at least 2 years, and tumors of similar histology in the absence of metastatic disease in intervening regional or mediastinal lymph node stations and the absence of extrathoracic disease. In addition, differing in histopathologic patterns of adenocarcinomas based on IASLC/ ATS/ERS classification subtypes (eg, different estimated percentages of acinar versus bronchoalveolar versus papillary adenocarcinoma) were also considered as independent primary tumors. ${ }^{5}$

A total of 182 patients were identified as second primary NSCLC. Of those, 115 patients had a second tumor with adenocarcinoma. All these patients had preoperative examination to exclude distant metastasis, which included chest computed tomography (CT) scan, abdominal CT or ultrasonography examination, brain magnetic resonance imaging, and whole body bone scan. Mediastinoscopy or endobronchial ultrasound-guided transbronchial needle aspiration or positron emission tomography was performed to exclude mediastinal lymphatic metastasis when the mediastinal lymph node enlargement (size $>1 \mathrm{~cm}$ ).

\section{Surgery}

Systematic and sampling lymph node dissection was performed in cases with lobar (lobectomy and extended lobectomy including sleeve lobectomy, lobectomy plus wedge resection, bilobectomy, and pneumonectomy) and sublobar (segmental and wedge resection), respectively.

\section{Histologic and pathologic evaluation}

One senior pathologist reviewed all hematoxylin and eosinstained slides and reevaluated histopathologic subtyping of lung adenocarcinoma according to the new classification. ${ }^{5}$ The tumor, node, and metastasis (TNM) stage was unified according to the seventh edition of the TNM classification for lung cancer. ${ }^{7}$

\section{Subgroups}

To increase the power of the analysis, three groups with low- (adenocarcinoma in situ, AIS; minimally invasive adenocarcinoma, MIA), intermediate- (lepidic-, acinar-, and papillary-predominant adenocarcinomas), and high-grade (solid-, micropapillary-, colloid-predominant, and invasive mucinous adenocarcinomas) adenocarcinomas were assigned for the patients with SPLAC according to the prognosis of IASLC/ATS/ERS classification subgroups reported by

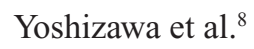

The second adenocarcinomas, based on the CT morphology and consolidation/tumor ratio, were further divided into ground glass opacity predominant (GGO-p; including pure GGO and consolidation/tumor ratio $\leq 50 \%$ GGO) and solid predominant (Solid-p; including tumors with consolidation/tumor ratio $>50 \%$ and pure solid).

\section{Statistical analysis}

Survival was calculated from the date of the second resection to the date of the last follow-up or death. Normally distributed continuous variables are presented as the mean \pm standard deviation, otherwise as the median and range, while categorical variables are presented as numbers and percentages. Cumulative survival rates were calculated by the Kaplan-Meier method and compared using the log-rank test. Multivariate analysis was conducted using the Cox proportional hazards model after backward stepwise Wald elimination. All tests were two-sided and the level of significance was defined as $P<0.05$. All statistical analysis was performed on SPSS version 19.0. 


\section{Results}

\section{Patient characteristics}

The clinical characteristics of patients are shown in Table 1. The median interval between the primary tumor resection and resection of the second tumor was 28 months (range, 5-122 months). Before the first surgical intervention, the mean forced expiratory volume in $1 \mathrm{~s}\left(\mathrm{FEV}_{1}\right)$ was $2393.1 \pm 437.9 \mathrm{~mL}(99.7 \%$ of predicted value; range, $1,620-3,360 \mathrm{~mL}, 82 \%-113.3 \%$ of predicted value). Before the second surgical intervention, most of the patients $(\mathrm{N}=98$; $85.2 \%$ ) had an $\mathrm{FEV}_{1}>60 \%$.

Table I Perioperative characteristics of the second intervention $(\mathrm{N}=\mid \mathrm{I5})$

\begin{tabular}{|c|c|c|}
\hline Variables & $\begin{array}{l}\text { First resection, } \\
\text { n (\%) }\end{array}$ & $\begin{array}{l}\text { Second resection, } \\
\text { n (\%) }\end{array}$ \\
\hline \multicolumn{3}{|l|}{$\operatorname{Sex}(\%)$} \\
\hline Male & & $55(47.8)$ \\
\hline Female & & $60(52.2)$ \\
\hline \multicolumn{3}{|l|}{ Age (years) } \\
\hline Median (range) & & $60.0(36-78)$ \\
\hline \multicolumn{3}{|l|}{ Smoking history } \\
\hline Never & & $80(69.6)$ \\
\hline Ever & & $35(30.4)$ \\
\hline \multicolumn{3}{|l|}{$\mathrm{FEV}_{1}(\%)$} \\
\hline$\leq 60$ & & $17(14.8)$ \\
\hline$>60$ & & $98(85.2)$ \\
\hline \multicolumn{3}{|l|}{ Tumor-free interval (years) } \\
\hline$<2$ & & $63(54.8)$ \\
\hline$\geq 2$ & & $52(45.2)$ \\
\hline \multicolumn{3}{|l|}{ Surgical approach } \\
\hline Thoracotomy & & $28(24.3)$ \\
\hline Video-assisted & & $87(75.7)$ \\
\hline \multicolumn{3}{|l|}{ thoracoscopic surgery } \\
\hline \multicolumn{3}{|c|}{ Adjuvant chemotherapy after first/second resection } \\
\hline Yes & $32(27.8)$ & $40(34.8)$ \\
\hline No & $83(72.2)$ & $75(65.2)$ \\
\hline \multicolumn{3}{|c|}{ ECOG PS before second resection } \\
\hline $0-1$ & $80(69.6)$ & \\
\hline 2 & $35(30.4)$ & \\
\hline \multicolumn{3}{|l|}{ Location } \\
\hline Ipsilateral & $39(33.9)$ & \\
\hline Contralateral & $76(66.1)$ & \\
\hline \multicolumn{3}{|c|}{ Computed tomography morphology } \\
\hline GGO-p & $46(40)$ & $73(63.5)$ \\
\hline Solid-p & $69(60)$ & $42(36.5)$ \\
\hline \multicolumn{3}{|l|}{ Type of resection } \\
\hline Sublobar resection & $21(18.3)$ & $58(50.4)$ \\
\hline Wedge & $18(15.7)$ & $37(32.2)$ \\
\hline Segmentectomy & $3(2.6)$ & $21(18.3)$ \\
\hline Lobar resection & $94(81.7)$ & $57(49.6)$ \\
\hline Lobectomy & $88(76.5)$ & $56(48.7)$ \\
\hline Extended lobectomy & $3(2.6)$ & I (0.9) \\
\hline
\end{tabular}

Abbreviations: ECOG, Eastern Cooperative Oncology Group; FEV , forced expiratory volume in I s; GGO-p, ground glass opacity predominant; PS, performance status; Solid-p, solid predominant.
The histopathologic distribution of the first and second resections was shown in Table 2. With respect to the second resections, according to the prognostic of IASLC/ATS/ERS classification subtypes, three subgroups with low- (AIS, $\mathrm{n}=6$; MIA, $\mathrm{n}=19$ ), intermediate- (lepidic, $\mathrm{n}=9$; acinar, $\mathrm{n}=40$; papillary, $n=23$ ), and high-grades (solid, $n=9$; micropapillary, $\mathrm{n}=2$; invasive mucinous, $\mathrm{n}=7$ ) were assigned (Table 3 ). Patients in the high-grade subgroup had the highest incidence of visceral pleura invasion (VPI; 44.4\%), followed by the intermediate-grade subgroup (22.2\%). There was no VPI in the low-grade subgroup. The high-grade subgroup was associated with more advanced pathologic stage.

\section{Follow-up and survival}

The median follow-up time was 80 months (range, 17-191 months) after the first resection and 44 months (range, $12-125$ months) after the second resection. By the time of the final follow-up, 33 patients had died. The 5-year overall survival (OS) rates from the time of the first and the second

Table 2 Histology of first and second resections

\begin{tabular}{|c|c|c|}
\hline Histology & First resection, $\mathbf{n}(\%)$ & Second resection, n (\%) \\
\hline Same/similar & $93(80.9)$ & \\
\hline AIS & I $(0.9)$ & $6(5.2)$ \\
\hline MIA & $8(7.0)$ & $19(16.5)$ \\
\hline Lepidic & $7(6.1)$ & $9(7.8)$ \\
\hline Acinar & $38(33.0)$ & $38(33.0)$ \\
\hline Papillary & $30(26.1)$ & $25(21.7)$ \\
\hline Solid & $6(5.2)$ & $9(7.8)$ \\
\hline Micropapillary & $\mathrm{I}(0.9)$ & $2(1.7)$ \\
\hline Mucinous & $2(1.7)$ & $7(6.1)$ \\
\hline Different & $22(19.1)$ & \\
\hline SCC-AC & I3 (II.3) & \\
\hline AS-AC & $6(5.2)$ & \\
\hline LC-AC & $3(1.7)$ & \\
\hline \multicolumn{3}{|l|}{ T stage } \\
\hline Tla & $36(3 \mid .3)$ & $54(47.0)$ \\
\hline TIb & $25(21.7)$ & $13(1 \mid .3)$ \\
\hline $\mathrm{T} 2 \mathrm{a}$ & $49(42.6)$ & $44(38.3)$ \\
\hline $\mathrm{T} 2 \mathrm{~b}$ & $2(1.7)$ & $2(1.7)$ \\
\hline T3 & $3(2.6)$ & $2(1.7)$ \\
\hline \multicolumn{3}{|l|}{$\mathrm{N}$ stage } \\
\hline No & $91(79.1)$ & 87 (75.7) \\
\hline $\mathrm{NI}$ & $27(20.9)$ & $16(13.9)$ \\
\hline N2 & 0 & $12(10.4)$ \\
\hline \multicolumn{3}{|l|}{ TNM stage } \\
\hline la & $57(49.6)$ & 7I (6I.7) \\
\hline $\mathrm{lb}$ & $31(27.0)$ & $18(15.7)$ \\
\hline Ila & $22(19.1)$ & II (9.6) \\
\hline Ilb & $5(4.3)$ & $2(I .7)$ \\
\hline Illa & 0 & $13(11.3)$ \\
\hline
\end{tabular}

Abbreviations: AC, adenocarcinoma; AIS, adenocarcinoma in situ; AS, adenosquamous carcinoma; LC, large cell carcinoma; MIA, minimally invasive adenocarcinoma; SCC, squamous cell carcinoma; TNM, tumor, node, and metastasis. 
Table 3 Correlation of the predominant histologic subtype with pathologic stage and survival

\begin{tabular}{|c|c|c|c|c|c|c|c|c|c|c|c|}
\hline Group & Total & VPI & No & NI & N2 & la & $\mathbf{l b}$ & Ila & Ilb & IIIa & 5-year OS \\
\hline Low grade & 25 & 0 & 25 & 0 & 0 & 25 & 0 & 0 & 0 & 0 & $-*$ \\
\hline AIS & 6 & 0 & 6 & 0 & 0 & 6 & 0 & 0 & 0 & 0 & \\
\hline MIA & 19 & 0 & 19 & 0 & 0 & 19 & 0 & 0 & 0 & 0 & \\
\hline Intermediate grade & 72 & 16 & 54 & 11 & 7 & 42 & 14 & 6 & 2 & 8 & $70.1 \%$ \\
\hline Lepidic & 9 & 3 & 4 & 3 & 2 & 3 & I & 3 & 0 & 2 & \\
\hline Acinar & 38 & 8 & 30 & 5 & 3 & 25 & 8 & 2 & 0 & 3 & \\
\hline Papillary & 25 & 5 & 20 & 3 & 2 & 14 & 5 & I & 2 & 3 & \\
\hline High grade & 18 & 8 & 8 & 5 & 5 & 4 & 4 & 5 & 0 & 5 & $33.0 \%$ \\
\hline Solid & 9 & 5 & 4 & 2 & 3 & I & 3 & 2 & 0 & 3 & \\
\hline Micropapillary & 2 & 1 & I & I & 0 & 0 & I & I & 0 & 0 & \\
\hline Mucinous & 7 & 2 & 3 & 2 & 2 & 3 & 0 & 2 & 0 & 2 & \\
\hline
\end{tabular}

Notes: *All data are censored. -, Not applicable, as more than half the number of patients were still alive.

Abbreviations: AIS, adenocarcinoma in situ; MIA, minimally invasive adenocarcinoma; VPI, visceral pleural invasion; OS, overall survival.

resections were $86.5 \%$ and $69.5 \%$, respectively. In addition, of the five patients harboring epidermal growth factor receptor mutation managed with epidermal growth factor receptor tyrosine kinase inhibitors after the second resections, four patients were alive with good quality of life at 28, 40, 64, and 125 months, respectively, while one died, living for 96 months due to brain metastasis.

There was no significant difference in OS $(P=0.888)$ between patients with an diagnosis interval $\leq 2$ and $>2$ years. The different types of the second resections demonstrated a slightly better 5 -year OS $(69.4 \%$ vs $63.6 \% ; P=0.067)$ in patients who underwent lobar resections compared with sublobar resections, but statistical significance was not achieved. Univariate analysis was shown in Table 4.

The different CT morphologies of the SPLAC demonstrated a significantly better OS in patients with GGO-p tumors compared with solid-p (adjusted hazard ratio $[\mathrm{HR}]=0.42 ; 95 \%$ confidence interval $[\mathrm{CI}], 0.19-0.94$; $P=0.036$; Figure 1). The pathologic stage of the primary tumor had a significant influence on the survival (adjusted $\mathrm{HR}=0.25 ; 95 \% \mathrm{CI}, 0.08-0.76 ; P=0.015$; Figure 2). Furthermore, patients with similar/same histology had a better OS than the different counterparts (adjusted $\mathrm{HR}=0.06 ; 95 \% \mathrm{CI}$, 0.02-0.18; $P<0.001$; Figure 3).

Patients in the low-grade subgroup were all alive (median follow-up, 42 months; range, $12-125$ months) by the time of the final follow-up evaluation, except the patient who died 101 months after the second section. Intermediate-grade subgroup had a 5 -year OS of $70.1 \%$. High-grade subgroup had a 5 -year OS of $42.2 \%$. There were significant differences with respect to OS between patients in the low- and highgrade subgroups (adjusted HR $=0.05 ; 95 \%$ CI, 0.01-0.58; $P=0.016$; Figure 2) and between the intermediate- and high-grade subgroup patients (adjusted $\mathrm{HR}=0.37 ; 95 \% \mathrm{CI}$,
$0.15-0.89 ; P=0.027$; Figure 4). Cox multivariate analysis was presented in Table 5 .

\section{Discussion}

A number of patients with primary multiple malignancies are on the rise due to prolonged survival and advances in diagnostic techniques. In this study, we highlighted SPLACs because adenocarcinoma accounts for the majority of reported MPLC cases, and previous outcomes are heterogeneous due to a variety of metachronous second malignancies are included. . $, 2,9-9-11^{-1}$

Adenocarcinoma has high morphologic heterogeneity, and the new adenocarcinoma classification proposed by the IASLC/ATS/ERS provided precise preoperative ${ }^{12}$ or intraoperative diagnoses, ${ }^{13}$ and appropriate extent of resection for various early-stage adenocarcinomas. ${ }^{13,14}$ There is mounting evidence showing that different histomorphologic patterns in lung adenocarcinomas can be used to define prognostically variable subsets, and differentiating between low- and high-risk lung adenocarcinomas are of high clinical importance in the management of early-stage lung adenocarcinomas. ${ }^{8,15-17}$ In the present study, three groups with low-, intermediate-, and high-grade adenocarcinomas were assigned for the patients with SPLACs according to the prognosis of IASLC/ATS/ERS classification subtypes.

As shown in previous studies, ${ }^{8,17}$ patients with solitary adenocarcinomas in the high-risk subgroup were associated with a high risk for recurrence or cancer-related death. The present study showed that patients with SPLACs in the high-grade group had the highest percentage of VPI, lymph node metastases, and relatively advanced pathologic stage, suggesting that this subgroup has a significant association with aggressive behavior that potentially favors early recurrence. Further analysis showed that there were significant 
Table 4 Univariate analysis of various potential prognostic factors for OS in patients with SPLAC

\begin{tabular}{|c|c|c|c|}
\hline Variable & $\begin{array}{l}\text { Patients } \\
\text { (n) }\end{array}$ & $\begin{array}{l}\text { Median OS } \\
\text { (months) }\end{array}$ & $P$-value \\
\hline Gender & & & 0.628 \\
\hline Male & 55 & $91.0 \pm 15.3$ & \\
\hline Female & 60 & $81.0 \pm 11.7$ & \\
\hline Age (years) & & & 0.679 \\
\hline$\leq 60$ & 61 & $81.0 \pm 16.2$ & \\
\hline$>60$ & 54 & $96.0 \pm 31.2$ & \\
\hline Smoking history & & & 0.824 \\
\hline Never & 80 & $81.0 \pm 12.7$ & \\
\hline Ever & 35 & $91.0 \pm 13.5$ & \\
\hline Interval (months) & & & 0.888 \\
\hline$\leq 24$ & 63 & $96.0 \pm 33.7$ & \\
\hline$>24$ & 52 & $81.0 \pm 12.6$ & \\
\hline ECOG PS & & & 0.054 \\
\hline $0-1$ & 80 & $91.0 \pm 17.7$ & \\
\hline 2 & 35 & $66.0 \pm 11.0$ & \\
\hline Type of the first resection & & & 0.072 \\
\hline Sublobar resection & 58 & $81.0 \pm 12.9$ & \\
\hline Lobar resection & 57 & $91.0 \pm 18.6$ & \\
\hline Type of the second resection & & & 0.206 \\
\hline Sublobar resection & 57 & $81.0 \pm 15.5$ & \\
\hline Lobar resection & 58 & $91.0 \pm 17.7$ & \\
\hline TNM stage of the primary tumor & & & $<0.00 I^{a}$ \\
\hline Stage I & & $101.0 \pm 5.8$ & \\
\hline Stage II & & $48.0 \pm 7.1$ & \\
\hline CT morphology of SPLAC & & & $0.00 I^{\mathrm{a}}$ \\
\hline GGO-p & 73 & $-^{\mathrm{b}}$ & \\
\hline Solid-p & 42 & $59.0 \pm 8.0$ & \\
\hline Location & & & 0.308 \\
\hline Ipsilateral & 39 & $67.0 \pm 27.5$ & \\
\hline Contralateral & 76 & 81.0 & \\
\hline Histologic classification & & & $0.00 \mathrm{I}^{\mathrm{a}}$ \\
\hline Similar/same & 93 & $96.0 \pm 6.3$ & \\
\hline Different & 22 & $48.0 \pm 7.2$ & \\
\hline TNM stage of SPLAC & & & $<0.00 I^{a}$ \\
\hline 1 & 83 & $-^{\mathrm{b}}$ & \\
\hline$\|$ & 19 & $66.0 \pm 11.2$ & \\
\hline IIla & 13 & $32.0 \pm 7.6$ & \\
\hline Histologic grade of SPLAC & & & $0.00 I^{a}$ \\
\hline Low & 25 & 101.0 & \\
\hline Intermediate & 72 & $91.0 \pm 15.7$ & \\
\hline High & 18 & $51.0 \pm 11.0$ & \\
\hline
\end{tabular}

Notes: ${ }^{a}$ Statistically significant. 'Median survival unable to be estimated. Data presented as mean \pm standard deviation. -, Not applicable, as more than half the number of patients were still alive.

Abbreviations: CT, computed tomography; ECOG, Eastern Cooperative Oncology Group; GGO-p, ground glass opacity predominant; MPLC, multiple primary lung cancer; OS, overall survival; PS, performance status; Solid-p, solid predominant; SPLAC, second primary lung adenocarcinoma; TNM, tumor, node, and metastasis.

differences in OS among patients in the low-, intermediate-, and high-grade subgroups when comparing the survival curves. Cox multivariate analysis identified histologic grade as a significant prognostic factor for OS, indicating that patients with SPLACs in the high-grade subgroup also have an increased risk for poor survival. The ongoing

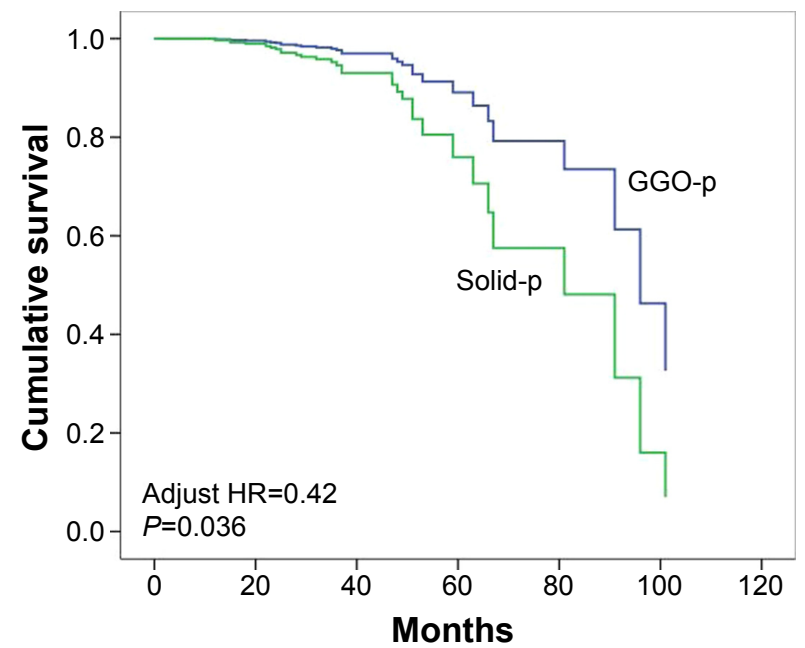

Figure I Survival comparisons according to tumor computed tomography morphologies of the second primary adenocarcinomas.

Abbreviations: GGO-p, ground glass opacity predominant; HR, hazard ratio; Solid-p, solid predominant.

investigations facilitated by this new classification system were expected to provide guidelines for better management of patients with SPLACs.

Surgery offers the best chance for potential cure of SPLACs and provides most sufficient samples for diagnosis. In this study, we have shown a 5 -year survival of $69.5 \%$ after resection of SPLACs, which was far better than expected for metastases or local recurrences.

Lobectomy remains the most effective treatment for patients with resectable primary NSCLCs. Although the survival outcomes of surgically treated MPLCs demonstrated in previous studies were very promising, ${ }^{9-11,18}$ standard surgical strategies and the optimal extent of resection for

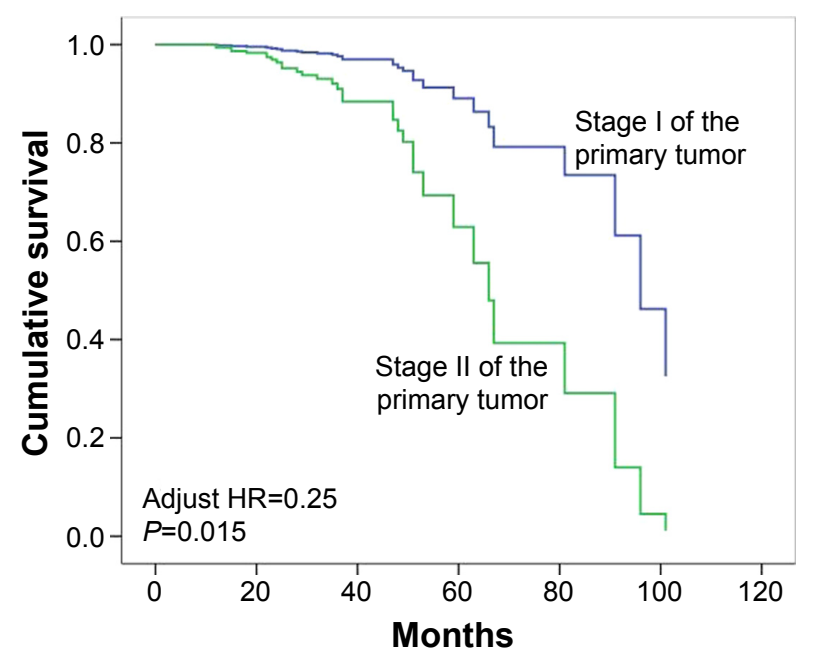

Figure 2 Survival comparisons based on the tumor, node, and metastasis stage of the second primary adenocarcinomas.

Abbreviation: HR, hazard ratio. 


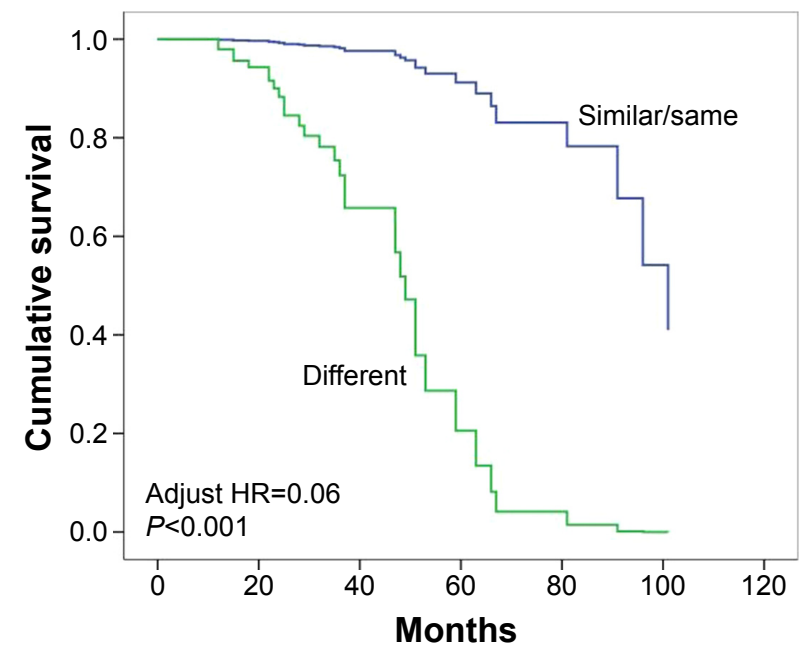

Figure 3 Survival comparisons based on the histologic classification. Abbreviation: $\mathrm{HR}$, hazard ratio.

the SPLCs have not been established owing to the lack of uniform criteria and prospective randomized trials. Generally, the extent of resection was based on the balance of risk and benefit of surgery, mainly considering characteristics of the tumor and performance status of patients, which might be different depending on individual surgeons. Regarding the extent of resection for the second tumors, the majority of the previous reports showed that sublobar resection is acceptable with comparable prognosis to anatomic lobar resections for SPLCs, appearing to support the use of limited resection in the treatment of metachronous lung cancer patients, ${ }^{1,4,10}$ which is inconsistent with some other studies. ${ }^{9,19}$ These outcomes are confusing because only the characteristics of the second tumor were analyzed and compared, even though the stage of the initial tumor might

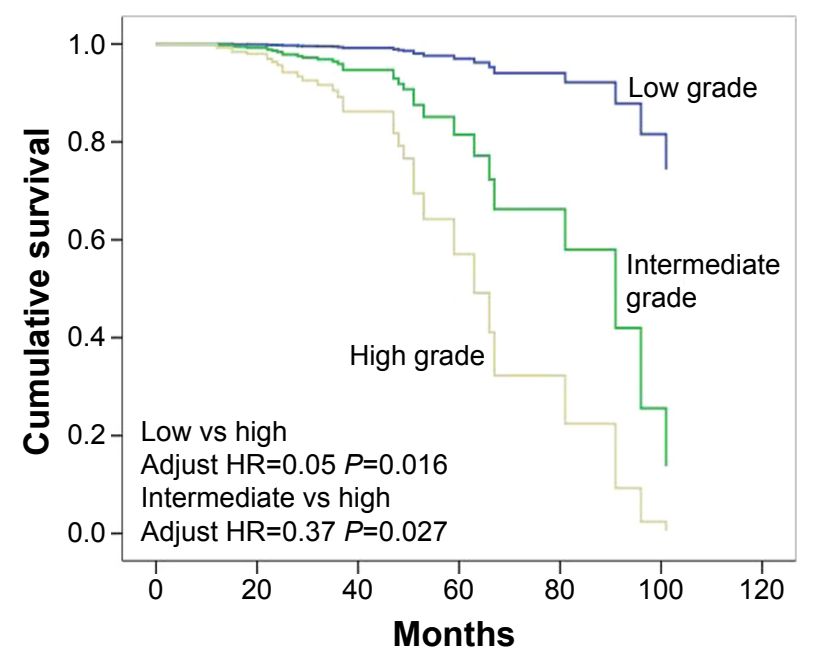

Figure 4 Survival comparisons according to histologic grade of the second primary adenocarcinomas.

Abbreviation: HR, hazard ratio.
Table 5 Cox proportional hazards model of factors associated with survival in patients with SPLAC

\begin{tabular}{|c|c|c|c|}
\hline \multirow[t]{2}{*}{ Characteristics } & \multicolumn{3}{|c|}{ Overall survival } \\
\hline & HR & $95 \% \mathrm{Cl}$ & $P$-value \\
\hline \multicolumn{4}{|l|}{ CT morphology of SPLAC } \\
\hline GGO-p & 0.42 & $0.19-0.94$ & 0.036 \\
\hline Solid-p & & Ref & \\
\hline \multicolumn{4}{|l|}{ Histology of MPLC } \\
\hline Similar/same & 0.06 & $0.02-0.18$ & $<0.001$ \\
\hline Different & & Ref & \\
\hline \multicolumn{4}{|c|}{ Pathologic stage of primary tumor } \\
\hline 1 & 0.25 & $0.08-0.76$ & 0.015 \\
\hline II & & Ref & \\
\hline Pathologic stage of SPLAC & & & 0.006 \\
\hline 1 & 0.21 & $0.08-0.56$ & 0.002 \\
\hline II & 0.53 & $0.20-1.38$ & 0.192 \\
\hline Illa & & Ref & \\
\hline Histologic grade & & & 0.019 \\
\hline Low & 0.05 & $0.01-0.58$ & 0.016 \\
\hline Intermediate & 0.37 & $0.15-0.89$ & 0.027 \\
\hline High & & Ref & \\
\hline
\end{tabular}

Abbreviations: $\mathrm{Cl}$, confidence interval; $\mathrm{CT}$, computed tomography; GGO-p, ground glass opacity predominant; HR, hazard ratio; MPLC, multiple primary lung cancer; Ref, reference; Solid-p, solid predominant; SPLAC, second primary lung adenocarcinoma.

potentially affect the prognosis and not be completely reliable for drawing conclusions.

The surgical extent and pathologic stage of the first tumor are two potential factors that significantly influence the prognosis of SPLAC patients. We attempted to reduce possible bias by including some important characteristics of the initially resected tumors.

In this study, the different types of second resections demonstrated a slightly better 5-year OS in patients who underwent lobar resections compared with sublobar resections, but it did not reach statistical significance. Multivariate analysis did not identify sublobar resection of the primary or second tumor as a significantly negative prognostic factor. In our series, most $(43 / 58,74.1 \%)$ of the sublobar resections of the second adenocarcinomas were performed after the new classification, which might be responsible for this nonsignificant difference between lobar and sublobar resections in that the new classification could provide an effective approach to guide the resection strategy for primary adenocarcinoma. ${ }^{13}$ However, considering that most of the patients with second lesions in this study underwent anatomic lobar resections rather than limited resections before 2011, and many patients in the low-risk subgroup who underwent sublobar resections had the very short duration of follow-up, thus the long-term prognosis for limited resections of second adenocarcinomas based on the new classification is remained unclear. As a result, a longer duration of follow-up is needed. Also, other 
characteristics of the initially resected tumor, such as tumor CT morphology, and histologic classifications could be potentially confounding factors, thus further studies are warranted with homogenizing characteristics of the first resection as much as possible. ${ }^{20}$ Stereotactic body radiotherapy (SBRT) has emerged as the standard treatment for medically inoperable early-staged NSCLC. ${ }^{21,22}$ The local control rate after SBRT is $>90 \%$. SBRT has also been widely adopted for the treatment of oligometastasis involving the lungs. Its possible applications in the treatment of SPLC are under extensive exploration.

Stage classification is essential because it allows consistent definition of patient groups, and thus provides a foundation for comparison of outcomes. For patients with MPLCs, however, the stage classification rules are ambiguous and confusing. Previous studies showed that pathologic stage of the second primary malignancies is demonstrated to be independent prognostic factor to predict survival without considering the potential influences caused by the stage of the first tumors. ${ }^{1,23}$ Our present study showed that both the pathologic stage of the first tumors and SPLACs significantly are prognostic factors, which further highlighted the complexity of MPLC staging. In this case, which one (initial versus second tumor) plays more important role in determining the prognosis of MPLCs or SPLACs requires further studies. Recently, proposals for the classification of lung cancers with multiple pulmonary sites of involvement in the forthcoming eighth edition of the TNM classification have been demonstrated, ${ }^{24}$ which might lead to greater consistency in classification of these multiple tumors while requiring further validations.

\section{Limitations}

There were several important potential limitations in this study. The sample size was very limited. Due to the retrospective nature of the study, the results were based on a highly selected group of patients, thus there was certainly a degree of selection bias in the study. Even after adjusting some potentially affected factors of the primary tumors, other characteristics, and surgical treatment of the initial lung cancer could also affect patient survival, leading to potential bias as well. There were no molecular and genetic characteristics available for differentiating multiple lung cancers in our study. Despite of the wide popularity of Martini-Melamed criteria and the promising survival, there is possibility that some cases of solitary pulmonary metastasis might exist within our series could be included. Thus, the assessment of mutation testing in patients with multiprimary adenocarcinomas is strongly suggested.

\section{Conclusion}

Surgical treatment can be considered for the management of SPLAC patients with promising survival outcomes. Tumor CT morphology of SPLACs and TNM status of the primary tumor and SPLACs were identified as predictors of long-term prognosis. The resection extent of primary tumor and SPLACs did not significantly affect 5-year survival of patients with SPLACs. The subgroups of SPLACs based on the new classification could provide additional prognostic information.

\section{Acknowledgments}

The authors are indebted to Keke Yu of Department of Pathology of Shanghai Chest Hospital, Shanghai Jiao Tong University for pathologic reassessment. This work was supported by National Natural Science Foundation of China under grant no 81572693 and Cross Foundation of Shanghai Jiao Tong University (YG2015ZD14).

\section{Disclosure}

The authors report no conflicts of interest in this work.

\section{References}

1. Yang J, Liu M, Fan J, et al. Surgical treatment of metachronous second primary lung cancer. Ann Thorac Surg. 2014;98(4):1192-1198.

2. Yang H, Sun Y, Yao F, et al. Surgical therapy for bilateral multiple primary lung cancer. Ann Thorac Surg. 2016;101(3):1145-1152.

3. Koezuka S, Hata Y, Otsuka H, et al. Metachronous second primary lung cancer surgically treated five years or more after the initial surgery. Mol Clin Oncol. 2015;3(5):1025-1028.

4. Hamaji M, Allen MS, Cassivi SD, et al. Surgical treatment of metachronous second primary lung cancer after complete resection of non-small cell lung cancer. J Thorac Cardiovasc Surg. 2013;145(3):683-690.

5. Travis WD, Brambilla E, Noguchi M, et al. International Association for the Study of Lung Cancer/American Thoracic Society/European Respiratory Society international multidisciplinary classification of lung adenocarcinoma. $J$ Thorac Oncol. 2011;6(2):244-285.

6. Martini N, Melamed MR. Multiple primary lung cancers. $J$ Thorac Cardiovasc Surg. 1975;70(4):606-612.

7. Goldstraw P, Crowley J, Chansky K, et al. The IASLC Lung Cancer Staging Project: proposals for the revision of the TNM stage groupings in the forthcoming (seventh) edition of the TNM classification of malignant tumours. J Thorac Oncol. 2007;2(8):706-714.

8. Yoshizawa A, Motoi N, Riely GJ, et al. Impact of proposed IASLC/ ATS/ERS classification of lung adenocarcinoma: prognostic sub-groups and implications for further revision of staging based on analysis of 514 stage I cases. Mod Pathol. 2011;24(5):653-664.

9. Zuin A, Andriolo LG, Marulli G, et al. Is lobectomy really more effective than sublobar resection in the surgical treatment of second primary lung cancer? Eur J Cardiothorac Surg. 2013;44(2):e120-e125.

10. Bae MK, Byun CS, Lee CY, et al. The role of surgical treatment in second primary lung cancer. Ann Thorac Surg. 2011;92(1):256-262.

11. De Leyn P, Moons J, Vansteenkiste J, et al. Survival after resection of synchronous bilateral lung cancer. Eur J Cardiothorac Surg. 2008; 34(6):1215-1222.

12. Takahashi M, Shigematsu Y, Ohta M, Tokumasu H, Matsukura T, Hirai T. Tumor invasiveness as defined by the newly proposed IASLC/ ATS/ERS classification has prognostic significance for pathologic stage Ia lung adenocarcinoma and can be predicted by radiologic parameters. J Thorac Cardiovasc Surg. 2014;147(1):54-59. 
13. Liu S, Wang R, Zhang $\mathrm{Y}$, et al. Precise diagnosis of intraoperative frozen section is an effective method to guide resection strategy for peripheral small-sized lung adenocarcinoma. J Clin Oncol. 2016;34(4): 307-313.

14. Van Schil PE, Asamura H, Rusch VW, et al. Surgical implications of the new IASLC/ATS/ERS adenocarcinoma classification. Eur Respir J. 2012;39(2):478-486.

15. Gu J, Lu C, Guo J, et al. Prognostic significance of the IASLC/ATS/ERS classification in Chinese patients - a single institution retrospective study of 292 lung adenocarcinoma. J Surg Oncol. 2013;107(5):474-480.

16. Warth A, Muley $\mathrm{T}$, Meister M, et al. The novel histologic International Association for the Study of Lung Cancer/American Thoracic Society/ European Respiratory Society classification system of lung adenocarcinoma is a stage-independent predictor of survival. J Clin Oncol. 2012; 30(13):1438-1446.

17. Russell PA, Wainer Z, Wright GM, et al. Does lung adenocarcinoma sub-type predict patient survival? A clinicopathologic study based on the new International Association for the Study of Lung Cancer/ American Thoracic Society/European Respiratory Society international multidisciplinary lung adenocarcinoma classification. J Thorac Oncol. 2011;6(9):1496-1504.

18. Yu YC, Hsu PK, Yeh YC, et al. Surgical results of synchronous multiple primary lung cancers: similar to the stage-matched solitary primary lung cancers? Ann Thorac Surg. 2013;96(6):1966-1974.
19. Doddoli C, Thomas P, Ghez O, Giudicelli R, Fuentes P. Surgical management of metachronous bronchial carcinoma. Eur J Cardiothorac Surg. 2001;19(6):899-903.

20. Hamaji M1, Ali SO, Burt BM. A meta-analysis of resected metachronous second non-small cell lung cancer. Ann Thorac Surg. 2015;99(4): 1470-1478.

21. Tsang MW. Stereotactic body radiotherapy: current strategies and future development. Thorac Dis. 2016;8(Suppl 6):S517-S527.

22. Louie AV, van Werkhoven E, Chen $\mathrm{H}$, et al. Patient reported outcomes following stereotactic ablative radiotherapy or surgery for stage IA nonsmall-cell lung cancer: results from the ROSEL multicenter randomized trial. Radiother Oncol. 2015;117(1):44-48.

23. Lee BE, Port JL, Stiles BM, et al. TNM stage is the most important determinant of survival in metachronous lung cancer. Ann Thorac Surg. 2009;88(4):1100-1105.

24. Detterbeck FC, Nicholson AG, Franklin WA, et al. The IASLC lung cancer staging project: summary of proposals for revisions of the classification of lung cancers with multiple pulmonary sites of involvement in the forthcoming eighth edition of the TNM classification. J Thorac Oncol. 2016;11(5):639-650.
OncoTargets and Therapy

\section{Publish your work in this journal}

OncoTargets and Therapy is an international, peer-reviewed, open access journal focusing on the pathological basis of all cancers, potential targets for therapy and treatment protocols employed to improve the management of cancer patients. The journal also focuses on the impact of management programs and new therapeutic agents and protocols on

\section{Dovepress}

patient perspectives such as quality of life, adherence and satisfaction. The manuscript management system is completely online and includes a very quick and fair peer-review system, which is all easy to use. Visit http://www.dovepress.com/testimonials.php to read real quotes from published authors. 